\title{
Oxytocin and emergency caesarean section in a medium- sized hospital in Pakistan: A cross-sectional study
}

\author{
Mirjam Lukasse ${ }^{1,2}$, Ingrid Hovda ${ }^{1}$, Sara Thommessen ${ }^{1}$, Sosan McAuley ${ }^{3}$, Marian Morrison ${ }^{3}$
}

\begin{abstract}
INTRODUCTION One of the most common complications during labor is prolonged labor (dystocia), which is associated with risks for the mother and fetus. Dystocia is usually treated with oxytocin, which is also used to induce labor. Oxytocin may not have the desired effect of progress and can negatively affect the fetus, thus resulting in an emergency caesarean section (CS). The aim of this study was to describe obstetric practice, use of oxytocin and its association with an emergency CS.

METHODS A cross-sectional retrospective register study was conducted that included all women who gave birth during 2014 and 2015 at a hospital in a large city in Pakistan.

RESULTS A total of 6652 women gave birth to 6767 newborns, $66.8 \%$ were multiparous and $33.2 \%$ primiparous women. Of the primiparous women, $78.9 \%$ had a spontaneous vaginal birth, $1.2 \%$ an elective CS and $14.4 \%$ an emergency CS. Of the multiparous women, $81.9 \%$ had a spontaneous vaginal birth, $8.0 \%$ an elective CS and $6.7 \%$ an emergency CS. Operative vaginal birth was $2.1 \%$ among primiparous and $0.2 \%$ among multiparous women. Oxytocin for induction or augmentation was administered to $60.0 \%$ of primiparous and $30.5 \%$ of multiparous women. Oxytocin during the first stage of labor was associated with an increased risk for emergency CS for both primiparous and multiparous women.
\end{abstract}

CONCLUSIONS Despite the association between oxytocin and emergency CS, the CS rate was low in this hospital. The majority of the women gave birth vaginally, even with a breech presentation. Few operative vaginal births were performed.

\section{AFFILIATION \\ 1 Institute of Nursing and Health Promotion, Faculty of Health Sciences, Oslo Metropolitan University, Oslo, Norway 2 Department of Nursing and Health Sciences, Faculty of Health and Social Sciences, University of South-Eastern Norway, Borre, Norway 3 Women's Christian Hospital, Multan, Pakistan}

\section{CORRESPONDENGE TO \\ Mirjam Lukasse. Department of Nursing and Health Sciences, Faculty of Health and Social Sciences, University of South- Eastern Norway, Raveien 215, Borre, 3184, Norway. E-mail: Mirjam.Lukasse@usn.no ORCID ID: https://orcid.org/0000- 0002-9873-4023}

\section{KEYWORDS \\ caesarean section, oxytocin, obstetric practice, Low-Middle- Income countries, Pakistan \\ Received: 17 February 2020 \\ Revised: 15 May 2020 \\ Accepted: 17 June 2020}

\section{INTRODUCTION}

Births assisted by skilled health personnel decrease the risk of maternal and neonatal mortality ${ }^{1-3}$. Efforts to increase births attended by skilled health professionals often lead to birth in a health facility/hospital ${ }^{3}$. Attendants in health facilities can intervene in case of complications ${ }^{4}$.

One of the most common complications during labor, in particular in primiparous women, is prolonged labor or dystocia ${ }^{5,6}$. Dystocia, also defined as less progress than expected or desired during a certain period of time, is associated with a number of complications such as maternal exhaustion, fetal hypoxia and asphyxia, and post- partum hemorrhage (PPH), and very occasionally ruptured uterus $^{5,7,8}$. Globally, dystocia is most commonly treated with the intravenous administration of oxytocin ${ }^{9-11}$. Besides being used for augmentation, oxytocin is commonly used for induction of labor, pre-labor rupture of membranes (PROM), and $\mathrm{PPH}^{9,12-15}$. Risks associated with the use of oxytocin are uterine hyper-stimulation, fetal hypoxia and asphyxia, uterine rupture and $\mathrm{PPH}^{9,16,17}$. Close monitoring of fetal heart rate and uterine activity by a skilled professional in a health facility is therefore recommended as long as infusion of oxytocin is ongoing ${ }^{9,16,17}$. In case where, despite the treatment with oxytocin, progression in labor fails, 
caesarean section (CS) is usually indicated ${ }^{17,18}$. The fetus can also react to (hyper) stimulation and become the reason for an emergency $\mathrm{CS}^{9,17,19}$. While oxytocin is a powerful and much used drug, there are concerns for its overuse ${ }^{9,20}$. The registration and monitoring of the use of interventions in obstetric care are part of essential quality control as well as registering obstetric and neonatal outcomes ${ }^{19,21}$.

There are numerous studies investigating obstetric care in Pakistan ${ }^{4,22,23}$. The rate of caesarean section, indications for CS, different methods for induction, associated factors with ruptured uterus and severe perineal trauma are among central obstetric issues investigated ${ }^{4,22-25}$. The majority of these studies were performed at university, public and teaching hospitals, or based on demographic health surveys ${ }^{4,22,23}$. We did not find any studies from Pakistan on the prevalence of intravenous oxytocin during labor and the association with emergency caesarean section (CS).

The first objective for this study was to present aspects of the obstetric care in a medium-sized, private hospital in a large city in Pakistan. The second objective was to explore the use of oxytocin and its association with emergency CS.

\section{METHODS}

This cross-sectional study used data routinely collected at the hospital. The data included all women who gave birth to 6767 babies in 2014 and 2015 (N=6652). Maternal age, gestational age, parity and the number of antenatal visits at the study hospital were recoded from a continuous variable into categorical/dichotomous variables as shown in Table 1. Mode of delivery was recoded into five groups: spontaneous vaginal birth, operative vaginal birth, vaginal breech delivery, elective CS and emergency CS. Perineal trauma and episiotomy was recoded into: episiotomy 'yes' or 'no', and perineal trauma by degree of tear. The number of fetuses, gender at birth, fetal presentation and/or lie and their state at birth (alive, stillbirth or neonatal death) was recorded. The use of oxytocin, the indication(s) and during which stage of labor it was administered was recorded. Indications for induction were categorized after primary indication. Fetal reasons for induction included intrauterine growth restriction, little fetal movement, oligohydramnios, post maturity and fetal death. Maternal reasons included diabetes and hypertensive complications. Doctors registered women as having a bad obstetric history when there was a history of multiple previous miscarriages, long infertility, previous stillbirths, neonatal deaths and previous small for dates baby and similar. Other methods for induction and augmentation were balloon catheter and orally misoprostol alone, or in addition to oxytocin. The primary indications for CS indication were used and categorized as shown in Table 1 .

\section{Characteristics of the hospital setting}

The hospital is located on the outskirts of a large city in the Punjab. The hospital uses paper partogram (data not available electronically) to record fetal heart rate, maternal temperature, pulse and blood pressure, frequency and strength of contractions, cervical effacement and dilatation, color of amniotic fluid, and drugs administered. The hospital defines established labor as regular uterine contractions every 5 minutes lasting at least 40 seconds. The strength and length of the contractions is assessed by palpation. Vaginal examinations are performed on admission and every 4 hours in established labor. Slow progress in established labor is defined as no progress within 4 hours, primarily measured by vaginal dilatation. Epidural analgesia was not an option. Fetal heart monitoring is done using pinards. Women have a female relative with them at all times. A student midwife is by the side of a woman almost constantly, while staff midwives cover several students and women.

The hospital has one procedure for the administration of oxytocin, used for both induction and augmentation. Administration of oxytocin to women PROM is described as augmentation. Administration of oxytocin has to be prescribed by a doctor or senior midwife on duty. Administration of oxytocin started with 5 units of oxytocin in $1000 \mathrm{~mL}$ intravenous fluid, starting with 10 drops per minute and doubling the number of drops every 15 minutes, to a maximum of $40 \mathrm{drops} / \mathrm{min}$. After 15 minutes with 40 drops/min, 5 units oxytocin was added in the same bag of IV fluids every 15 minutes until labor/regular strong contractions were established, or the maximum dose of 20 units oxytocin at $40 \mathrm{drops} / \mathrm{min}$ was reached. No electronic pumps are available for the titration of intravenous fluids. Oxytocin is usually continued until the third stage of labor is completed. Dosage is reduced if indicated by fetal or maternal response.

The study was approved by the Regional Ethical Committee South-Eastern Norway, Number 2018/516. Approval for the study was given from the board of the hospital and the ethical committee of the hospital in Pakistan. All data in the study were routinely collected and had no negative impact on the patients or the personnel at the hospital. Sensitive data were removed from the dataset and the data were anonymized prior to transfer to Norway for analysis.

\section{Statistical methods}

The Statistical Package for the Social Sciences (SPSS, version 24) was used for the analysis and a p-value of 0.05 was used as a cut-off for significance. All women were included in the cross tabulations for Table 1. P-values were calculated using Pearson chi-squared test and Fisher's exact test ( $<5$ values in a cell). Elective CS and multiple pregnancies were excluded from the analyses on the use of oxytocin. Binary logistic regression analysis was used to estimate crude odds ratios (OR) and adjusted odds ratios (AOR) with $95 \%$ confidence intervals $(\mathrm{Cl})$, investigating the association between the use of oxytocin and emergency CS. Adjustments were made for maternal age, gestational age, birthweight in two groups, bad obstetric history, presentation/lie, and previous CS for multiparous women.

\section{RESULTS}

Of all 6652 woman who gave birth at the hospital in 2014 and 
Table 1. Background characteristics by parity on admission ( $N=6652)$

\begin{tabular}{|c|c|c|c|}
\hline & $\begin{array}{c}\text { Primiparous } \\
\text { women } \\
\begin{array}{c}n=2208 \\
n(\%)\end{array}\end{array}$ & $\begin{array}{c}\text { Multiparous } \\
\text { women } \\
n=4444 \\
n(\%)\end{array}$ & $\begin{array}{l}\text { Total } \\
\begin{array}{c}N=6652 \\
n(\%)\end{array}\end{array}$ \\
\hline \multicolumn{4}{|l|}{ Year } \\
\hline 2014 & $1153(52.2)$ & $2320(52.2)$ & $3473(52.2)$ \\
\hline 2015 & $1055(47.8)$ & $2124(47.8)$ & $3179(47.8)$ \\
\hline \multicolumn{4}{|l|}{ Maternal age (years) } \\
\hline$<20$ & $66(3.0)$ & $8(0.2$ & $74(1.1)$ \\
\hline $20-24$ & $956(43.3)$ & $777(17.5)$ & $1733(26.1)$ \\
\hline $25-29$ & 906 (41.0) & 1735 (39.0) & $2641(39.7)$ \\
\hline $30-37$ & $272(12.3)$ & $1752(39.4)$ & $2024(30.4)$ \\
\hline$>37$ & $8(0.4)$ & $172(3.9)$ & $180(2.7)$ \\
\hline \multicolumn{4}{|l|}{ Gestational age (weeks) $(n=6648)$} \\
\hline Preterm <37 & $251(11.4)$ & $537(12.1)$ & $788(11.9)$ \\
\hline Term 37-41 & $1939(87.8)$ & $3870(87.2)$ & $5809(87.4)$ \\
\hline Postdates $>41$ & $18(0.8)$ & $33(0.7)$ & $51(0.8)$ \\
\hline \multicolumn{4}{|l|}{ Antenatal visits at study hospital } \\
\hline 0 & $62(2.8)$ & $163(3.7)$ & $225(3.4)$ \\
\hline $1-3$ & $1081(49.0)$ & $2360(53.1)$ & $3441(51.7)$ \\
\hline$\geq 4$ & $1065(48.2)$ & $1921(43.2)$ & $2986(44.9)$ \\
\hline \multicolumn{4}{|c|}{ Number of fetuses in current pregnancy } \\
\hline One & $2176(97.0)$ & 4367 (96.5) & $6543(96.7)$ \\
\hline Two & $58(2.6)$ & $154(3.4)$ & $212(3.1)$ \\
\hline Three & $9(0.4)$ & $3(0.1)$ & $12(0.2)$ \\
\hline \multicolumn{4}{|c|}{ Number of previous spontaneous abortions } \\
\hline 0 & $1778(80.5)$ & $2778(62.5)$ & $4556(68.5)$ \\
\hline 1 & $259(11.7)$ & $992(22.3)$ & $1251(18.8)$ \\
\hline $2-4$ & $168(7.5)$ & $632(14.3)$ & $800(12.0)$ \\
\hline $5-10$ & $3(0.1)$ & $42(0.9)$ & $45(0.7)$ \\
\hline Previous bad obstetric history & $32(1.4)$ & $335(7.5)$ & $368(5.5)$ \\
\hline \multicolumn{4}{|c|}{$\begin{array}{l}\text { Number of previous caesarean sections } \\
\text { (multiparous only) }\end{array}$} \\
\hline 1 & & $449(10.1)$ & \\
\hline 2 & & $169(3.8)$ & \\
\hline 3 & & $63(1.4)$ & \\
\hline 4 & & $9(0.2)$ & \\
\hline
\end{tabular}

a Included all newborns: single, twins, and triplets $(n=6767)$.

2015, 33.2\% where primiparous and $66.8 \%$ were multiparous (Table 1). The mean maternal age for primiparous was 25.1 years $(S D=3.7)$ and for multiparous 28.7 years $(S D=4.6)$. Less than half of the women had $\geq 4$ antenatal visits and almost 12\% gave birth preterm (Table 1 ).

The overall CS rate was $15.0 \%$ with similar rates for primiparous and multiparous women but a different distribution for the proportion of elective CS and emergency CS (Table 2). There were no maternal deaths and no ruptured uterus in the study period. Of all babies, 130 were stillborn and 112 died before discharge, with no significant difference $(p=0.36)$ between primiparous and multiparous. Primiparous women were significantly more likely to have an episiotomy compared to multiparous women, $60.6 \%$ vs $2.0 \%$, respectively $(\mathrm{p}<0.001)$ (Table 2$)$.

Of all women, 2347 (38.0\%) were treated with oxytocin with primiparous women significantly more frequently receiving this treatment compared to multiparous, $60 \%$ vs $30.5 \%$, respectively (Table 3 ). Almost all women induced received oxytocin (96.9\%) while primiparous more frequently 
Table 2. Obstetric and neonatal outcomes by parity for 2014 and 2015 (N=6652)

\begin{tabular}{|c|c|c|c|}
\hline & $\begin{array}{c}\text { Primiparous } \\
\text { women } \\
n=2208 \\
n(\%)\end{array}$ & $\begin{array}{c}\text { Multiparous } \\
\text { women } \\
\begin{array}{c}n=4444 \\
n(\%)\end{array}\end{array}$ & $\begin{array}{c}\text { Total } \\
\begin{array}{c}N=6652 \\
n(\%)\end{array}\end{array}$ \\
\hline Mode of delivery ${ }^{a}$ & $n=2243$ & $n=4524$ & $n=6767$ \\
\hline Spontaneous vaginal delivery & $1768(78.9)$ & 3709 (81.9) & $5477(80.9)$ \\
\hline Vaginal breech delivery & $77(3.4)$ & $145(3.2)$ & $222(3.3)$ \\
\hline Emergency CS & $324(14.4)$ & $302(6.7)$ & $626(9.3)$ \\
\hline Elective CS & $27(1.2)$ & $361(8.0)$ & $388(5.7)$ \\
\hline Vaginal operative delivery (excluding breech) & $47(2.1)$ & $7(0.2)$ & $54(0.8)$ \\
\hline Indication for emergency CS & $n=324$ & $n=302$ & $n=626$ \\
\hline No progress & $230(71.0)$ & $148(49.0)$ & $378(60.3)$ \\
\hline Previous CS & $\mathrm{O}(0.0)$ & $22(7.3)$ & $22(3.5)$ \\
\hline Malpresentation & $11(3.4)$ & $67(22.2)$ & $78(12.5)$ \\
\hline Fetal reason & $52(16.0)$ & $23(7.6)$ & 75 (12.0) \\
\hline Maternal reason & $18(5.6)$ & $29(9.6)$ & $47(7.5)$ \\
\hline Not registered & $13(4.0)$ & $13(4.3)$ & $26(4.2)$ \\
\hline Birthweight $(\mathrm{g})^{\mathbf{a}}$ & $n=2243$ & $n=4524$ & $n=6767$ \\
\hline Low <2500 & $395(17.6)$ & $634(14.0)$ & $1029(15.2)$ \\
\hline Normal $\geq 2500$ & $1848(82.4)$ & $3890(86.0)$ & $5738(84.8)$ \\
\hline Neonatal outcome ${ }^{a}$ & $n=2243$ & $n=4524$ & $n=6767$ \\
\hline Alive & $2156(96.1)$ & 4369 (96.6) & $6525(96.4)$ \\
\hline Dead & $87(3.9)$ & $155(3.4)$ & $242(3.6)$ \\
\hline Still birth & $49(56.3)$ & $81(52.3)$ & $130(53.7)$ \\
\hline Neonatal death & $38(43.7)$ & $74(47.7)$ & $112(46.3)$ \\
\hline Gendera & $n=2243$ & $n=4524$ & $n=6767$ \\
\hline Female & $1122(50.0)$ & $2086(46.1)$ & $3208(47.4)$ \\
\hline Male & $1121(50.0)$ & $2433(53.8)$ & $3554(52.5)$ \\
\hline Uncertain & $\mathrm{O}(0.0)$ & $5(0.1)$ & $5(0.1)$ \\
\hline Presentation/lie ${ }^{a}$ & $n=2243$ & $n=4524$ & $n=6767$ \\
\hline Vertex & $2110(94.1)$ & $4238(93.7)$ & $6348(93.8)$ \\
\hline Face & $4(0.1)$ & $7(0.2)$ & $11(0.1)$ \\
\hline Breech & $129(5.8)$ & 265 (5.9) & $394(5.8)$ \\
\hline Transverse & $\mathrm{O}(0.0)$ & $14(0.3)$ & $14(0.2)$ \\
\hline $\mathrm{PPH}>1000 \mathrm{~mL}$ & $19(0.9)$ & $38(0.9)$ & $57(0.9)$ \\
\hline Episiotomy ${ }^{b}$ & 1338 (61.3) & $91(2.2)$ & $1429(22.8)$ \\
\hline \multicolumn{4}{|l|}{ Tears in perineum ${ }^{c}$} \\
\hline Grade 1 & 78 (3.6) & $182(4.5)$ & $260(4.1)$ \\
\hline Grade 2 & $27(1.2)$ & $50(1.2)$ & 77 (1.2) \\
\hline Grade 3 & $\mathrm{O}(0.0)$ & $4(0.1)$ & $4(0.06)$ \\
\hline
\end{tabular}

a Included all newborns ( $\mathrm{n}=6767)$. b Proportion calculated excluding elective caesarian section (CS). c Alone or in addition to an episiotomy, proportion excluding elective CS.

received misoprostol in addition (Table 3). Of the women with a spontaneous start of labor, including PROM, 1277 (25.7\%) were augmented with oxytocin. Significantly more primiparous than multiparous women were augmented, $42.5 \%(749 / 1760)$ vs $16.1 \%$ (528/3277), respectively $(p<0.001)$. Excluding women with PROM from spontaneous start of labor 16.5\% (741/4481) were augmented, 13.8\% started in first stage and $2.6 \%$ in second stage. Almost ten per cent (9.4\%) of preterm births at the hospital were induced, most due to preeclampsia (29.7\%), intrauterine growth restriction (24.7\%), and stillbirths (21.6\%) (data not in table). 
Table 3. Status on admission, induction and augmentation in labor $(N=6172)^{a}$

\begin{tabular}{|c|c|c|c|c|}
\hline & $\begin{array}{c}\text { Primiparous } \\
\text { women } \\
\begin{array}{c}n=2151 \\
n(\%)\end{array}\end{array}$ & $\begin{array}{c}\text { Multiparous } \\
\text { women } \\
\begin{array}{c}n=4021 \\
n(\%)\end{array}\end{array}$ & $\begin{array}{c}\text { Total } \\
\begin{array}{c}\text { N=6172 } \\
n(\%)\end{array}\end{array}$ & $p$ \\
\hline Status on admission & $n=2151$ & $n=4021$ & $N=6172$ & \\
\hline Spontaneous start of labor ${ }^{b}$ & $1760(81.8)$ & $3277(81.4)$ & $5037(81.6)$ & 0.762 \\
\hline Admitted for induction & $378(17.6)$ & 718 (17.9) & $1096(17.8)$ & \\
\hline Missing (not elective CS) & $13(0.6)$ & $26(0.7)$ & $33(0.6)$ & \\
\hline Induction method & $n=378$ & $\mathrm{n}=718$ & $n=1096$ & \\
\hline Oxytocin only & $136(36.0)$ & $418(58.3)$ & $554(50.5)$ & $<0.001$ \\
\hline Misoprostol & $10(2.6)$ & $19(2.6)$ & $29(2.6)$ & \\
\hline Misoprostol \& oxytocin & $231(61.1)$ & $277(38.6)$ & $508(46.4)$ & \\
\hline Balloon catheter & $0(0.0)$ & $1(0.1)$ & $1(0.1)$ & \\
\hline Balloon catheter \& oxytocin & $1(0.3)$ & $3(0.4)$ & $4(0.4)$ & \\
\hline Gestational age at induction (weeks) & $n=378$ & $\mathrm{n}=718$ & $n=1096$ & \\
\hline$<37$ & $25(6.6)$ & $47(6.5)$ & $72(6.6)$ & 0.360 \\
\hline $37-41$ & $341(90.2)$ & $656(91.4)$ & 997 (90.9) & \\
\hline$>41$ & $12(3.2)$ & $13(1.8)$ & $25(2.3)$ & \\
\hline Not registered & $\mathrm{O}(0.0)$ & $2(0.3)$ & $2(0.2)$ & \\
\hline Primary indication for induction & $\mathrm{n}=378$ & $n=718$ & $n=1096$ & \\
\hline Fetal reasons & $257(67.9)$ & $261(36.4)$ & $518(47.3)$ & $<0.001$ \\
\hline Maternal reasons & $83(22.0)$ & $133(18.5)$ & $216(19.7)$ & \\
\hline Bad obstetric history & $25(6.6)$ & $316(44.0)$ & $341(31.1)$ & \\
\hline Other & $1(0.3)$ & $0(0.0)$ & $1(0.1)$ & \\
\hline Not registered & $12(3.2)$ & $8(1.1)$ & $20(1.8)$ & \\
\hline Augmentation of labor & $758(35.2)$ & $539(13.4)$ & $1297(21.0)$ & $<0.001$ \\
\hline Method and timing of augmentation & $n=758$ & $n=539$ & $n=1297$ & \\
\hline Oxytocin after $\mathrm{PROM}^{\mathrm{C}}$ & $246(32.5)$ & $195(36.2)$ & $441(34.0)$ & 0.360 \\
\hline Oxytocin in first stage of labor ${ }^{c}$ & $359(47.3)$ & $262(48.7)$ & $621(47.9)$ & \\
\hline Oxytocin in second stage of labor ${ }^{c}$ & $77(10.2)$ & $43(8.0)$ & $120(9.3)$ & \\
\hline Oxytocin \& misoprostol after ruptured membranes & $67(8.8)$ & $28(5.1)$ & $95(7.3)$ & \\
\hline Misoprostol after ruptured membranes & $9(1.2)$ & $11(2.0)$ & $20(1.5)$ & \\
\hline Primary indication for augmentation & $n=758$ & $n=539$ & $n=1297$ & \\
\hline Ruptured membranes no contractions & $322(42.5)$ & $234(43.4)$ & $556(42.9)$ & 0.415 \\
\hline Slow progress in Stage 1 & $359(47.3)$ & $261(48.4)$ & $620(47.7)$ & \\
\hline Slow progress in Stage 2 & $77(10.2)$ & $43(8.0)$ & $120(9.3)$ & \\
\hline Not registered & $\mathrm{O}(0.0)$ & $1(0.2)$ & $1(0.1)$ & \\
\hline Infusion with oxytocin & $n=1117$ & $n=1226$ & $n=2343$ & $<0.001$ \\
\hline Induced & $368(33.0)$ & 698 (56.9) & 1066 (45.5) & \\
\hline Augmented only & 749 (67.0) & $528(43.1)$ & $1277(54.5)$ & \\
\hline
\end{tabular}

a Multiple pregnancies and elective CS excluded. b Augmentation after Pre-labor Rupture of Membranes (PROM) is included in spontaneous start of labor as per hospital protocol. c Oxytocin only.

Among primiparous women, the use of oxytocin for induction, PROM and in the first stage of labor was associated with an increased risk for emergency CS: (AOR=6.01; 95 \%Cl: 4.29-8.42), (AOR=2.43; 95\% Cl: 1.66$3.56)$ and $(A O R=1.80 ; 95 \% \mathrm{Cl}: 1.21-2.68)$, respectively
(Table 4).

Among multiparous women, only the use of oxytocin for induction and PROM was associated with an increased risk for emergency CS: (AOR=2.72; 95\% Cl: 1.78-4.13) and (AOR=2.05; 95\% Cl: 1.18-3.55), respectively (Table 5). 
Table 4. Oxytocin and other associated factors with birth by emergency caesarean section in primiparous women $(N=2151)^{a}$

\begin{tabular}{|c|c|c|c|}
\hline & $\begin{array}{c}\text { Emergency CS } \\
n=316\end{array}$ & Crude OR (95\% CI) & $\operatorname{AOR}(95 \% \mathrm{CI})^{b}$ \\
\hline Oxytocin only $(n=309)^{c}$ & n (\%) & & \\
\hline \multicolumn{4}{|c|}{ Use of oxytocin and reason } \\
\hline Ruptured membranes & $57(18.4)$ & $3.29(2.52-4.30)$ & $2.43(1.66-3.56)$ \\
\hline Stage 1 & $47(15.2)$ & $2.09(1.57-2.78)$ & $1.80(1.21-2.68)$ \\
\hline Stage 2 & $6(1.9)$ & $1.70(0.93-3.12)$ & $0.95(0.40-2.28)$ \\
\hline Induced & $123(39.9)$ & $4.04(3.30-4.95)$ & $6.01(4.29-8.42)$ \\
\hline No oxytocin & $76(24.6)$ & Ref. & Ref. \\
\hline \multicolumn{4}{|l|}{ Maternal age (years) } \\
\hline$<25$ & $118(37.3)$ & $0.65(0.51-0.83)$ & $0.81(0.62-1.05)$ \\
\hline $25-37$ & $195(61.8)$ & Ref. & Ref. \\
\hline$\geq 38$ & $3(0.9)$ & $4.86(0.97-24.24)$ & $2.87(0.43-19.10)$ \\
\hline \multicolumn{4}{|c|}{ Gestational age (weeks) } \\
\hline$<37$ & $27(8.5)$ & $0.76(0.50-1.16)$ & $0.92(0.58-1.47)$ \\
\hline $37-41$ & $285(90.2)$ & Ref. & Ref. \\
\hline$\geq 42$ & $4(1.3)$ & $1.62(0.53-4.97)$ & $0.75(0.23-2.46)$ \\
\hline \multicolumn{4}{|l|}{ Birthweight (g) } \\
\hline$<3650$ & $267(84.5)$ & Ref. & Ref. \\
\hline$\geq 3650$ & $49(15.5)$ & $3.60(2.48-5.22)$ & $3.57(2.40-5.32)$ \\
\hline \multicolumn{4}{|l|}{ Bad obstetric history } \\
\hline Yes & $11(3.5)$ & $3.12(1.49-6.53)$ & $1.05(0.48-2.32)$ \\
\hline No & $305(96.5)$ & Ref. & Ref. \\
\hline \multicolumn{4}{|l|}{ Presentation/lie } \\
\hline Vertex & $282(89.2)$ & Ref. & Ref. \\
\hline No vertex & $34(10.8)$ & $3.13(2.04-4.82)$ & $3.36(2.07-5.46)$ \\
\hline
\end{tabular}

a Excluding multiple pregnancies and elective CS. b Controlled for all variables in the table. c Use of oxytocin not registered for 7 primiparous women. AOR: adjusted odds ratio.

Table 5. Oxytocin and other associated factors and birth by emergency caesarean section in multiparous women $(N=4021)^{a}$

\begin{tabular}{|c|c|c|c|}
\hline & $\begin{array}{c}\text { Emergency CS } \\
n=273\end{array}$ & Crude OR $(95 \%$ CI) & AOR $(95 \% C I)^{b}$ \\
\hline Oxytocin only $(n=254) c$ & n (\%) & & \\
\hline \multicolumn{4}{|c|}{ Use of oxytocin and reason } \\
\hline Ruptured membranes & $22(8.7)$ & $2.12(1.31-3.38)$ & $2.05(1.18-3.55)$ \\
\hline Stage 1 & $20(7.8)$ & $1.59(0.98-2.59)$ & $1.27(0.74-2.18)$ \\
\hline Stage 2 & $4(1.6)$ & $1.98(0.70-5.61)$ & $2.33(0.73-7.43)$ \\
\hline Induced & $71(28.0)$ & $2.18(1.62-2.94)$ & $2.72(1.78-4.13)$ \\
\hline No oxytocin & $137(53.9)$ & Ref. & Ref. \\
\hline \multicolumn{4}{|l|}{ Maternal age (years) } \\
\hline$<25$ & $30(11.0)$ & $0.55(0.37-0.82)$ & $0.64(0.41-1.01)$ \\
\hline $25-37$ & 224 (82.0) & Ref. & Ref. \\
\hline$\geq 38$ & $19(7.0)$ & $1.93(1.17-3.19)$ & $1.85(1.02-3.34)$ \\
\hline
\end{tabular}


Table 5. Continued

\begin{tabular}{|c|c|c|c|}
\hline & $\begin{array}{c}\text { Emergency CS } \\
n=273\end{array}$ & Crude OR (95\% CI) & $\operatorname{AOR}(95 \% \mathrm{CI})^{b}$ \\
\hline \multicolumn{4}{|c|}{ Gestational age (weeks) $(n=272)$} \\
\hline$<37$ & $49(18.0)$ & $1.72(1.25-2.39)$ & $1.71(1.14-2.56)$ \\
\hline $37-41$ & $219(80.5)$ & Ref. & Ref. \\
\hline$\geq 42$ & $4(1.5)$ & $2.15(0.75-6.17)$ & $1.01(0.29-3.52)$ \\
\hline \multicolumn{4}{|l|}{ Birthweight (g) } \\
\hline$<3650$ & $219(80.2)$ & Ref. & Ref. \\
\hline$\geq 3650$ & $54(19.8)$ & $1.81(1.32-2.47)$ & $2.12(1.46-3.10)$ \\
\hline \multicolumn{4}{|c|}{ Bad obstetric history } \\
\hline Yes & $29(10.6)$ & $1.37(0.92-2.05)$ & $1.13(0.64-1.99)$ \\
\hline No & $244(89.4)$ & Ref. & Ref. \\
\hline \multicolumn{4}{|c|}{ Previous caesarean section } \\
\hline$\geq 1$ previous CS & $142(52.1)$ & $16.73(12.74-21.97)$ & 21.95 (16.10-29.94) \\
\hline No & $131(47.9)$ & Ref. & Ref. \\
\hline \multicolumn{4}{|c|}{ Presentation/lie } \\
\hline Vertex & $225(82.4)$ & Ref. & Ref. \\
\hline No vertex & $48(17.6)$ & $6.24(4.35-8.93)$ & $7.54(4.76-11.95)$ \\
\hline
\end{tabular}

a Excluding multiple pregnancies and elective CS. b Controlled for all variables in the table. c Use of oxytocin not registered for 19 multiparous women. AOR: adjusted odds ratio.

\section{DIScUSSION}

The present study found a high standard of care at this hospital, as observed by the rate of spontaneous vaginal births and caesarean sections, perinatal mortality rate, and no cases of ruptured uterus or maternal mortalities. Vaginal breech delivery was common, while operative vaginal births were few. In particular, primiparous women were prone to receive interventions such as oxytocin and episiotomy. Oxytocin for induction had the strongest association with emergency CS, especially for primiparous women. Oxytocin for PROM was associated with double the odds of an emergency CS, for both primiparous and multiparous women. Oxytocin in the second stage of labor was not associated with an increased risk of an emergency CS.

We found the strongest association to be between the use of oxytocin for induction and emergency CS. This is not strange as inducing labor requires an indication. Usually, the indication in itself already increases the odds for a birth by $\mathrm{CS}^{26}$. We found that the adjusted odds of an emergency CS were six-fold for induced primiparous women. These increased odds are considerably larger than the doubling of the odds reported by the authors of a large cross-sectional study of routinely collected data in Australia of primiparous women at term ${ }^{27}$. However, this Australian study selected a 'standard primipara' excluding any complication or factors that could cause complications, which could explain some of the difference ${ }^{27}$.

Among the multiparous women there was a two-fold increase in odds for an emergency CS due to induction. This is in line with other retrospective studies, which consistently demonstrate a higher CS rate following induction ${ }^{28}$. In contrast, evidence from prospective studies suggests that compared to expectant management, induction of labor in women with intact membranes reduces the risk of $\mathrm{CS}^{29}$.

The hospital follows the WHO recommendations for induction of labor, including the need for a clear medical indication ${ }^{17}$. This may be reflected in the rate of induction in this study. Adding the number of women who received oxytocin for PROM to the number of women induced, as is common internationally, the proportion of induction was $23.1 \%$ at the study hospital. This is similar to the US with $23.8 \%$ in $2015^{30}$, and a little less than in England in 2014$2015^{31}$. Rates in low-and-middle-income countries vary, but are usually lower than in high-income countries ${ }^{17}$.

Among primiparous women augmentation with oxytocin in first stage of labor was associated with increased odds. Similar to induction, the reason for slow progress may become the reason for emergency CS. As oxytocin is a powerful drug with potential serious side-effects, minimizing its use is generally advised ${ }^{32}$. The rate of augmentation, excluding PROM, induction, multiple pregnancy and elective CS, was $16.6 \%$ (741/4481) for all, 10\% for multiparous, and $29.9 \%$ for primiparous women. This is similar to the findings in the population-based large cohort study from England, the Birthplace study, which reported an incidence of 9.8/100 for multiparous women and 34/100 for nulliparous women planning to give birth in an obstetric unit ${ }^{33}$. In contrast to our study, the Birthplace study had a selected population of low-risk women. Judicious use of oxytocin has been associated with a reduction in emergency 
CS in several studies ${ }^{32}$ while other studies have found no increase in $\mathrm{CS}^{34}$. There were no cases of ruptured uterus among women receiving oxytocin, suggesting careful use of oxytocin at the study site, in particular when over half of the multiparous women had a previous CS.

The rate of episiotomies among primiparous women was considerably higher than the rates found in many high-income countries and recommendations found in the literature ${ }^{35,36}$. Probably, as a result, there were few 1st and 2 nd degree tears (5.2 \%). Cases of anal sphincter trauma were rare $(0.1 \%)$. While this might suggest that in this hospital the high rate of episiotomy prevents $3 \mathrm{rd}$ and 4th degree tears, it could also indicate that cases of anal sphincter trauma go undiagnosed. There were less than $1 \%$ vaginal operative deliveries performed during the study period. This may, in part, explain the extremely low prevalence of anal sphincter trauma. The proportion of vaginal operative deliveries varies greatly across countries and hospitals and appears to be declining across the globe ${ }^{37,38}$. Performing fewer operative deliveries poses a challenge, as staff will become less skilled, and confident and education opportunities decrease ${ }^{38}$. In contrast, there were a relative high number of vaginal breech deliveries during the study period, 222 (3.3\%), a rate which is decreasing in high-income countries ${ }^{39}$.

\section{Strengths and limitations}

A definite strength of the current study is the quality of the data used for analysis, except for $\mathrm{PPH}$. The number of women registered with $\mathrm{PPH}>1000 \mathrm{~mL}$ of less than $1 \%$ is likely the result of underestimation and/or lack of reporting. The retrospective design meant that no Hawthorn effect has improved the findings due to increased focus. The study included a large number of women, which provided the opportunity to describe aspects of the obstetric care at the hospital and perform adjusted regression analyses. However, we only investigated data from 2 years and do not know if the rates of interventions in this hospital are developing over time. The registered data lacked information on socioeconomic background, education, body mass index (BMI) and obstetric outcomes such as Apgar score, which is a weakness of the study.

\section{CONGLUSIONS}

The caesarean section rate of this hospital is in line with the recommendations of the $\mathrm{WHO}$. This study found that the use of oxytocin during labor is associated with an increased risk for birth by emergency CS. Women who received oxytocin for induction had highest risk for emergency CS, in particular among primiparous women. This information can be used when advising women about induction. The findings of this study will stimulate continued careful recording and further and more detailed investigation of obstetric and midwifery practice at the study site.

\section{REFERENGES}

1. Snow RC, Laski L, Mutumba M. Sexual and reproductive health: Progress and outstanding needs. Global Public Health. 2015;10(2):149-173. doi:10.1080/17441692.2014.986178

2. McClure EM, Saleem S, Goudar SS, et al. Stillbirth rates in low-middle income countries 2010 - 2013: a population-based, multi-country study from the Global Network. Reproductive health. 2015;12(Suppl 2):S7. doi:10.1186/1742-4755-12-S2-S7

3. Agha S. Impact of a maternal health voucher scheme on institutional delivery among low income women in Pakistan. Reprod Health. 2011;8(1):10. doi:10.1186/1742-4755-8-10

4. Abbas F, Ud Din RA, Sadiq M. Prevalence and determinants of Caesarean delivery in Punjab, Pakistan. East Mediterr Health J. 2019;24(11):1058-1065. doi:10.26719/2018.24.11.1058

5. Nystedt A, Hildingsson I. Diverse definitions of prolonged labour and its consequences with sometimes subsequent inappropriate treatment. BMC Pregnancy Childbirth. 2014;14(10):233. doi:10.1186/1471-2393-14-233

6. Karacam Z, Walsh D, Bugg GJ. Evolving understanding and treatment of labour dystocia. Eur J Obstet Gynecol Reprod Biol. 2014;182:123-127. doi:10.1016/j.ejogrb.2014.09.011

7. Vachon-Marceau C, Demers S, Goyet M, Gauthier R, Roberge S, Chaillet N, et al. Labor Dystocia and the Risk of Uterine Rupture in Women with Prior Cesarean. Am J Perinatol. 2016;33(6):577-583. doi:10.1055/s-0035-1570382

8. Kjaergaard H, Olsen J, Ottesen B, Dykes AK. Incidence and outcomes of dystocia in the active phase of labor in term nulliparous women with spontaneous labor onset. Acta Obstet Gynecol Scand. 2009;88(4):402-407. doi:10.1080/00016340902811001

9. Drummond S. Oxytocin Use in Labor: Legal Implications. $J$ Perinat Neonatal Nurs. 2018;32(1):34-42. doi:10.1097/JPN.0000000000000300

10. Bugg GJ, Siddiqui F, Thornton JG. Oxytocin versus no treatment or delayed treatment for slow progress in the first stage of spontaneous labour. Cochrane Database Syst Rev. 2013(6):CD007123. doi:10.1002/14651858.CD007123.pub3

11. Wei S, Wo BL, Qi HP, et al. Early amniotomy and early oxytocin for prevention of, or therapy for, delay in first stage spontaneous labour compared with routine care. Cochrane Database Syst Rev. 2013(8):CD006794. doi:10.1002/14651858.CD006794.pub4

12. Mozurkewich EL, Chilimigras JL, Berman DR, Perni UC, Romero VC, King VJ, et al. Methods of induction of labour: a systematic review. BMC Pregnancy Childbirth. 2011;11(1):84. doi:10.1186/1471-2393-11-84

13. Middleton P, Shepherd E, Flenady V, McBain RD, Crowther CA. Planned early birth versus expectant management (waiting) for prelabour rupture of membranes at term (37 weeks or more). Cochrane Database Syst Rev. 2017(1):166. doi:10.1002/14651858.CD004735.pub4

14. Oladapo OT, Okusanya BO, Abalos E. Intramuscular versus intravenous prophylactic oxytocin for the third stage of labour. Cochrane Database Syst Rev. 2018;9:CD009332. doi:10.1002/14651858.CD009332.pub3 
15. Qazi Q, Akhtar Z, Khan K, Khan AH. Woman health: uterus rupture, its complications and management in teaching hospital Bannu, Pakistan. Maedica (Buchar). 2012;7(1):49-53. PMID:23118819.

16. Rousseau A, Burguet A. Oxytocin administration during spontaneous labor: Guidelines for clinical practice. Chapter 5: Maternal risk and adverse effects of using oxytocin augmentation during spontaneous labor. J Gynecol Obstet Hum Reprod. 2017;46(6):509-521. doi:10.1016/j.jogoh.2017.04.012

17. World Health Organization. Sexual and reproductive health: WHO Recommendations for Induction of labour. https://apps.who.int/iris/bitstream/ handle/10665/44531/9789241501156eng.pdf ;jsessionid=4132 A9E60110DA6FE25CBAC143802 DE3? sequence $=1$. Published 2011. Accessed May 15, 2020.

18. Bernitz S, Dalbye R, Zhang J, et al. The frequency of intrapartum caesarean section use with the WHO partograph versus Zhang's guideline in the Labour Progression Study (LaPS): a multicentre, cluster-randomised controlled trial. Lancet. 2019;393(10169):340-348. doi:10.1016/ S0140-6736(18)31991-3

19. Simpson KR, James DC. Effects of oxytocin-induced uterine hyperstimulation during labor on fetal oxygen status and fetal heart rate patterns. Am J Obstet Gynecol. 2008;199(1):34e1-34e5. doi:10.1016/j.ajog.2007.12.015

20. Kenyon S, Tokumasu H, Dowswell T, Pledge D, Mori R. Highdose versus low-dose oxytocin for augmentation of delayed labour. Cochrane Database Syst Rev. 2013(7):CD007201. doi:10.1002/14651858.CD007201.pub3

21. Seijmonsbergen-Schermers $A$, van den Akker $T$, Beeckman K, Bogaerts A, Barros M, Janssen P, et al. Variations in childbirth interventions in highincome countries: protocol for a multinational crosssectional study. BMJ Open. 2018;8(1):e017993. doi:10.1136/bmjopen-2017-017993

22. Aziz N, Yousfani S. Analysis of uterine rupture at university teaching hospital Pakistan. Pak J Med Sci. 2015;31(4):920-924. doi:10.12669/pjms.314.7303

23. Amjad A, Amjad U, Zakar R, Usman A, Zakar MZ, Fischer F. Factors associated with caesarean deliveries among child-bearing women in Pakistan: secondary analysis of data from the Demographic and Health Survey, 2012-13. BMC Pregnancy Childbirth. 2018;18(1):113. doi:10.1186/s12884-018-1743-z

24. Bhutta ZA, Hafeez A, Rizvi A, Ali N, Khan A, Ahmad F, et al. Reproductive, maternal, newborn, and child health in Pakistan: challenges and opportunities. Lancet. 2013;381(9884):2207-2218. doi:10.1016/S0140-6736(12)61999-0

25. Atif K, Naqvi SS, Hassan Naqvi SA, Ehsan K, Niazi SA, Javed A. Reproductive health issues in Pakistan; do myths take precedence over medical evidence? J Pak Med Assoc. 2017;67(8):1232-1237. PMID:28839310.

26. de Vries BS, Barratt A, McGeechan K, Tooher J, Wong E, Phipps $H$, et al. Outcomes of induction of labour in nulliparous women at 38 to 39 weeks pregnancy by clinical indication: An observational study. Aust N Z J Obstet Gynaecol. 2019;59(4):484-492. doi:10.1111/ajo.12930

27. Davey MA, King J. Caesarean section following induction of labour in uncomplicated first births- a population-based cross-sectional analysis of 42,950 births. BMC Pregnancy Childbirth. 2016;16(1):92. doi:10.1186/s12884-016-0869-0

28. Levine LD, Hirshberg A, Srinivas SK. Term induction of labor and risk of cesarean delivery by parity. J Matern Fetal Neonatal Med. 2014;27(12):1232-1236. doi:10.3109/14767058.2013.864274

29. Wood S, Cooper S, Ross S. Does induction of labour increase the risk of caesarean section? A systematic review and meta-analysis of trials in women with intact membranes. BJOG. 2014;121(6):674-685. doi:10.1111/1471-0528.12328

30. Martin JA, Hamilton BE, Osterman MJK, Driscoll AK, Mathews TJ. Births: Final Data for 2015. In: National Vital Statistics Reports. https://www.cdc.gov/nchs/ data/nvsr/nvsr66/nvsr66_01.pdf. Published January 5, 2017. Accessed May 15, 2020.

31. National Health Service. NHS Maternity Statistics, England 2017-18. https://digital.nhs.uk/data-andinformation/publications/statistical/nhs-maternitystatistics/2017-18. Published October 25, 2018. Accessed May 15, 2020.

32. Rossen J, Ostborg TB, Lindtjorn E, Schulz J, Eggebo TM. Judicious use of oxytocin augmentation for the management of prolonged labor. Acta Obstet Gynecol Scand. 2016;95(3):355-361. doi:10.1111/aogs.12821

33. de Jonge A, Peters L, Geerts CC, van Roosmalen JJM, Twisk JWR, Brocklehurst P, et al. Mode of birth and medical interventions among women at low risk of complications: A cross-national comparison of birth settings in England and the Netherlands. PLoS One. 2017;12(7):e0180846. doi:10.1371/journal.pone.0180846

34. Gaudernack LC, Froslie KF, Michelsen TM, Voldner N, Lukasse $M$. De-medicalization of birth by reducing the use of oxytocin for augmentation among first-time mothers - a prospective intervention study. BMC Pregnancy Childbirth. 2018;18(1):76. doi:10.1186/s12884-018-1706-4

35. Clesse C, Lighezzolo-Alnot J, De Lavergne S, Hamlin S, Scheffler M. Statistical trends of episiotomy around the world: Comparative systematic review of changing practices. Health Care Women Int. 2018;39(6):644662. doi:10.1080/07399332.2018.1445253

36. Jiang H, Qian X, Carroli G, Garner P. Selective versus routine use of episiotomy for vaginal birth. Cochrane Database Syst Rev. 2017;2:CD000081. doi:10.1002/14651858.CD000081

37. Harrison MS, Saleem S, Ali S, et al. A Prospective, Population-Based Study of Trends in Operative Vaginal Delivery Compared to Cesarean Delivery Rates in Low- and Middle-Income Countries, 2010-2016. Am J Perinatol. 
2018;12(S2). doi:10.1186/1742-4755-12-S2-S9

38. Merriam AA, Ananth CV, Wright JD, Siddiq Z, D'Alton ME, Friedman AM. Trends in operative vaginal delivery, 20052013: a population-based study. BJOG. 2017;124(9):13651372. doi:10.1111/1471-0528.14553

39. Hehir MP. Trends in vaginal breech delivery. J Epidemiol Community Health. 2015;69(12):1237-1239. doi:10.1136/jech-2015-205592

\section{CONFLICTS OF INTEREST}

The authors have completed and submitted the ICMJE Form for Disclosure of Potential Conflicts of Interest and none was reported.

\section{FUNDING}

Research time for ML was paid by Oslo Metropolitan University.

\section{AUTHORS' CONTRIBUTIONS}

$M L, M M, I H$ and SB perceived the design of the study. MM and SMcA collected the data. $\mathrm{IH}$ and SB cleaned the data and performed the analyses agreed upon by all authors. $\mathrm{IH}, \mathrm{SB}$, $\mathrm{ML}, \mathrm{SMcA}$ and MM interpreted the results. ML, $\mathrm{H}$ and SB were involved in the writing of the manuscript. All authors approved the final manuscript.

\section{PROVENANGE AND PEER REVIEW}

Not commissioned; externally peer reviewed. 